\title{
Material Selection in Engineering Design Using Choquet Integral-Based Linguistic Operators under Hybrid Environment
}

\author{
Anhua Peng, Xiqin Wen, and Kaibo Wu \\ Engineering Training Center, Huaihai Institute of Technology, Lianyungang, Jiangsu 222005, China \\ Correspondence should be addressed to Anhua Peng; pah7301@126.com
}

Received 27 March 2015; Revised 1 July 2015; Accepted 14 July 2015

Academic Editor: Kalyana C. Veluvolu

Copyright (c) 2015 Anhua Peng et al. This is an open access article distributed under the Creative Commons Attribution License, which permits unrestricted use, distribution, and reproduction in any medium, provided the original work is properly cited.

\begin{abstract}
The performance of phase change materials directly influences the performance and cost of thermal energy storage, and it is the first important task to select the suitable phase change materials for use in a particular kind of applications. Due to the decision maker's knowledge field and the nature of evaluated attributes, assessments are always with different formats, which were first unified into the linguistic terms in the basic linguistic term set. Two-additive fuzzy measures were used to model criteria interactions by pairs, and the special expressions of Marichal entropy and Choquet integral were derived, more convenient to use in practice. Fuzzy measures were identified based on the maximum of Marichal entropy, and, based on the Choquet integral, the linguistic hybrid weighted geometric averaging with interaction was developed for integrating the individual attributes' ratings. The detailed decision making procedure was illustrated, with the material $33.2 \mathrm{Cu}$ as the optimal solution, which by comparison is reasonable and trustworthy.
\end{abstract}

\section{Introduction}

Engineering design draws on tens of thousands of materials and on many hundreds of processes to shape, join, and finish them. One aspect of optimized design of a product or system is that of selecting, from this vast menu, the materials and processes that best meet the needs of the design, maximizing its performance and minimizing its cost. The selection of the most appropriate materials not only affects the capability of manufacturing systems and satisfaction of customers but also impacts environmental issues. Furthermore, material selection is the prerequisite for a chain of different engineering selection problems, for instance, process selection and machine selection. As pointed out by Tawancy et al. in [1], the variation in material and design resulted in significant difference in service performance: The pipe using heat-resistant casting steel failed after only $22,000 \mathrm{~h}$ of service while that using wrought INCOLOY alloy $800 \mathrm{H}$ remained in operation for $83,000 \mathrm{~h}$. Therefore, material selection plays an important role in product cost and performance throughout its life cycle. An ever increasing variety of materials is available today, with each having its own characteristics, applications, advantages, and limitations. There is no material which satisfies all the relevant properties. For example, some materials are good enough to satisfy cost-related criteria but not so good in terms of some mechanical criteria, while some are good to satisfy a set of thermal criteria but not suitable in terms of cost, and so on. The large number of materials available to designers, coupled with complex interrelationship between the different selection parameters, often makes the material selection process a difficult task. The traditional material selection methods, such as those based only on designers' experiences, try-and-error methods, or analogy methods, are often made in the following way: one chooses between a few materials which have been used for similar situations before. This often leads to a conservative choice and one also misses newly developed materials which may be suitable for the new modified situation.

To ease out the material selection procedure and make the right decision, a systematic and efficient approach is required. According to literature retrieval, these methods can roughly be classified as material selection charts, knowledge-based methods, and multiattribute decision making (MADM). Ashby has suggested material selection chart, also known as 
Ashby chart, for selecting materials in a given application, and it is widely used in the literature as [2]. However, drawing the Ashby chart requires a broad engineering knowledge, which sometimes makes it difficult for a practitioner to employ the method, and the material selection procedure is performed based on two performance indices per chart. Consequently, if more than two performance indices are required to be considered, then it should be done using a sequential process. In addition, Ashby's charts normally offer a range or a list of materials to the designers to choose from, so they can only be used in material screening, not in material ranking. Fuzzy inference systems (FIS) and genetic algorithm (GA) are two typical knowledge-based methods and can be found widely used in material selection as in $[3,4]$. However, a limitation of the FIS is that the inclusion of a new criterion increases exponentially the number of decision rules of an inference system. The main drawback of GA is that it requires users to have a level of specialized knowledge that is likely to be well beyond that possessed by most managers and organizational decision makers. Also a severe drawback of GA is that some feasible solutions cannot be generated by crossover operation [5]. As stated in [6], this research provides evidence that the MADM approaches have potential to greatly improve the material selection methodology, which motivates this paper to use MADM to address the phase change material selection problem.

Much literature using MADM deals with the material selection. However, in most of the literature on the material selection, only one kind of ratings for attributes was considered. In the literature [7], three kinds of ratings for attributes are considered: exact values, intervals, and linguistic terms, but employing the method of computing the interval distance to normalize, although simple in calculation, loses a lot of useful information. As stated in [8], some of these attributes can be expressed as numbers, like density or thermal conductivity; some are Boolean, such as the ability to be recycled; some, like resistance to corrosion, can be expressed only as a ranking (e.g., poor, adequate, and good); and some can only be captured in text and images. Moreover, in the material selection process especially in the initial screening stage, the growing complexity and uncertainty of decision situations make it less and less possible for a decision maker to consider all relevant aspects of a problem and necessitate the participation of multiple experts in decision making to consider every aspect completely, draw on collective wisdom, absorb all useful ideas, and finally improve decision making results. Due to the decision maker's knowledge field, attitudes, motivations, and personality and the nature of evaluated attributes, the decision makers may provide the assessments with different formats. Such a type of MADM problems is called the fuzzy heterogeneous MADM problems with which seldom literature deals [9]. Consequently, it is very necessary and important to develop a normalization method which deals with the fuzzy heterogeneous information. In this paper, a method is proposed to transform the heterogeneous information to linguistic terms in the basic linguistic term set (BLTS).

Many ranking methods have been developed to aggregate each attribute's rating for all alternatives, which can be classified as two different approaches: compensatory and noncompensatory models. Whether compensatory methods or noncompensatory methods, most of the ranking methods regard attribute's relationships as independent. To all intents and purposes, the relationships among many attributes exhibit interdependences with various degrees, such as the relationship between hardness and elastic modulus, increased hardness usually leading to decreased elastic modulus, and that between strength and elongation at break, increased strength usually leading to decreased elongation at break. This has also given rise to the attention of many experts. As argued by Jahan et al. in [10], it can be highlighted that the correlation between criteria is realistic in material selection; thus ranking of materials without attention to the dependency of material properties causes doubtable final solution. As proposed by Karande et al. in [11], future research may aim at improving these methods so that the possible correlation between the considered criteria can be taken into account for arriving at the best material selection decision. Liu et al. in [12] proposed that considering the interrelationship of the material indices is one of the subjects that should receive some more attention in the process of material selection. It is indeed true, for a decision making model considering interdependences among attributes is more scientific, accurate than that not considering interdependences, which is only a special case in decision making problems. Jahan et al. in [10] proposed the correlation effects weighting to mitigate the effect of interdependences where the attribute with the greater intercriteria correlation with the other attributes was assigned a smaller correlation effects weighting. Peng and Xiao in [7] proposed the analytic network process (ANP), a relatively new MADM method based on analytic hierarchy process (AHP), to consider the feedback and interactions within and between sets of design criteria and alternatives. However, the ANP can only identify whether or not a criterion is affected by the corresponding control criterion but cannot identify whether the interactions between any two criteria are positive (superadditive) or negative (subadditive), and with ANP decision makers must construct so many comparison matrices, which incurs great burdens on the decision makers.

In 1974, Sugeno introduced the concept of fuzzy measures, substituting the additive rigid constraints in classical theory of probability with monotony with weaker constraints, and in the process of MADM employing the integration operators based on fuzzy measures and integral not only takes into account the relative weights but also flexibly represents and treats any interactions among attributes. To the best knowledge of the authors, to date, no paper on material selection has used them to deal with the interdependences among attributes. Some literature as in [13] applied Choquet integrals to supplier selection but under the presupposition that the fuzzy measures are already known or are only subjectively identified by experts, yet actually whether or not the fuzzy measures are accurate directly determines the accuracy of fuzzy integrals, and therefore how to determine the fuzzy measures is the key step. Literature [14], and so forth, employed $\lambda$ fuzzy measures to identify fuzzy measures for each attribute or attribute coalition, but although it can 
greatly reduce the difficulty in identifying fuzzy measures, it can only express one kind of interactions, either all with positive interactions or with negative interactions, abating the power of interaction expressions and violating the actual situations. In this paper, to better capture the interactions among attributes, two-additive fuzzy measures were used to model criteria interactions by pairs and to derive the special expressions of Marichal entropy and Choquet integral, more convenient to use in practice. Fuzzy measures were identified based on the maximum of Marichal entropy. Two Choquet integral-based operators were proposed to obtain the overall ratings of each alternative, which were then used to sort all alternatives.

\section{Transforming Hybrid Information into Linguistic Terms in BLTS}

2.1. Linguistic Terms. When an attribute is related to qualitative aspects, it may be difficult to qualify it using some values, and it is very convenient to express with linguistic terms (e.g., when evaluating chemical stability of a material, terms like "very good," " good," "average," " bad," or "very bad" can be used). Suppose $S=\left\{s_{0}, s_{1}, \ldots, s_{H}\right\}$ is a finite and total discrete term set, where the middle term represents "average," that is, a probability of approximately 0.5 , and the remaining terms are ordered symmetrically around it. As for the properties of a linguistic term, refer to [15].

With literature retrieval, four ways can be found to treat the linguistic variables: (i) based on the extension principle, (ii) based on the symbolic model, (iii) based on virtual linguistic terms, and (iv) based on 2-tuple fuzzy linguistic representation $\left(s_{k}, a_{k}\right.$ ) (where $s_{k}$ is a linguistic label from a predefined linguistic term set $S ; a_{k}, a_{k} \in[-0.5,0.5)$, denotes the value of symbolic translation, particularly $a_{k}=0$ in a predefined linguistic term set). Since the first two methods take an approximation process, this inevitably produces the consequent information loss and hence the lack of precision. In comparison 2-tuple fuzzy linguistic representation involves no approximation process, does not give rise to information loss, is explicit enough in physical meanings, and therefore is used in this paper. Let $\beta, \beta \in[0, H]$ be the result of an aggregation of the indices of a set of labels assessed in a linguistic term set $S$, that is, the result of a symbolic aggregation operation, with $H+1$ as the cardinality of set $S$. Then $\beta$ can be represented as 2 -tuple $\left(s_{k}, a_{k}\right)$ using the function $\Delta[16]$ :

$$
\begin{aligned}
& \Delta:[0, H] \longrightarrow S \times[-0.5,0.5), \\
& \Delta(\beta)= \begin{cases}s_{k} & k=\operatorname{round}(\beta) \\
a_{k}=\beta-k & a_{k} \in[-0.5,0.5),\end{cases}
\end{aligned}
$$

where $\operatorname{round}(\beta)$ is the usual round operation, $s_{k}$ has the closest index label to $\beta$, and $a_{k}$ denotes the difference between $\beta$ and $k$ in $\{0,1, \ldots, H\}$. Conversely let $\left(s_{k}, a_{k}\right)$ be a 2 -tuple linguistic term; then $\left(s_{k}, a_{k}\right)$ can be represented as equivalent numerical value, $\beta \in[0, H]$, using the inverse function $\Delta^{-1}$ [16]:

$$
\begin{aligned}
\Delta^{-1}: S \times[-0.5,0.5) & \longrightarrow[0, H], \\
\Delta^{-1}\left(s_{k}, a_{k}\right) & =k+a_{k}=\beta .
\end{aligned}
$$

2.2. Making the Linguistic Terms Uniformed. For group decision making problems, experts may express linguistic preferences over attributes or alternatives with different cardinalities, so in the process of information integration we should first uniform the linguistic terms with different cardinalities into the ones in the BLTS. Let $S_{[0, \ldots, H-1]}^{H}$ be BLTS with cardinality of $H$, and source linguistic term $\left(s_{k}^{G}, a_{k}\right)$ in set $S_{[0, \ldots, G-1]}^{G}$ can be equivalently transformed into $\left(s_{k^{\prime}}^{\prime}, a_{k^{\prime}}\right)$ in the BLTS using the following function [7]:

$$
\left(s_{k^{\prime}}^{\prime}, a_{k^{\prime}}\right)=\Delta\left(\beta^{\prime}\right)=\Delta\left(\frac{\Delta^{-1}\left(s_{k}^{G}, a_{k}\right)(H-1)}{G-1}\right) .
$$

The transformation function enjoys good properties of the one-to-one characteristic and simple calculation process and can do the inverse operation.

\subsection{Transforming the Other Information}

2.3.1. Normalization. Suppose $f_{i j}$ is the rating of alternative $o_{i}(i=1,2, \ldots, m)$ in respect of criterion $c_{j}(j=1,2, \ldots, n)$. Generally, criteria can be classified into two types: benefit $\left(\Omega_{1}\right)$ and cost $\left(\Omega_{2}\right)$ criteria. The larger the value of an alternative on the benefit criterion, the better the alternative, while the smaller the value of an alternative on the cost criterion, the better the alternative. If $f_{i j}$ is a triangular fuzzy number then it is denoted by $u_{\tilde{b}_{i j}}(x)=\left(b_{i j}^{l}, b_{i j}^{m}, b_{i j}^{u}\right)$, or $\widetilde{b}_{i j}=$ $\left(b_{i j}^{l}, b_{i j}^{m}, b_{i j}^{u}\right)$ for short, whose membership function is given as follows:

$$
u_{\tilde{b}_{i j}}(x)= \begin{cases}\frac{\left(x-b_{i j}^{l}\right)}{\left(b_{i j}^{m}-b_{i j}^{l}\right)} & \text { if } b_{i j}^{l} \leq x<b_{i j}^{m} \\ 1 & \text { if } x=b_{i j}^{m} \\ \frac{\left(b_{i j}^{u}-x\right)}{\left(b_{i j}^{u}-b_{i j}^{m}\right)} & \text { if } b_{i j}^{m}<x \leq b_{i j}^{u} .\end{cases}
$$

If $f_{i j}$ is an interval number then it is denoted by $u_{\widehat{h}_{i j}}(x)=$ $\left(h_{i j}^{l}, h_{i j}^{u}\right)$, or $\widehat{h}_{i j}=\left[h_{i j}^{l}, h_{i j}^{u}\right]$ for short, whose membership function is given as follows:

$$
u_{\widehat{h}_{i j}}(x)= \begin{cases}1 & \text { if } h_{i j}^{l} \leq x \leq h_{i j}^{u} \\ 0 & \text { if } x \in \text { others. }\end{cases}
$$

Since the physical dimensions and measurements of the $n$ attributes are different, the raw data need to be normalized. 
For a triangular fuzzy number $\widetilde{b}_{i j}=\left(b_{i j}^{l}, b_{i j}^{m}, b_{i j}^{u}\right)$, it can be normalized as follows [9]:

$$
\begin{aligned}
& \tilde{b}_{i j}^{*}
\end{aligned}
$$

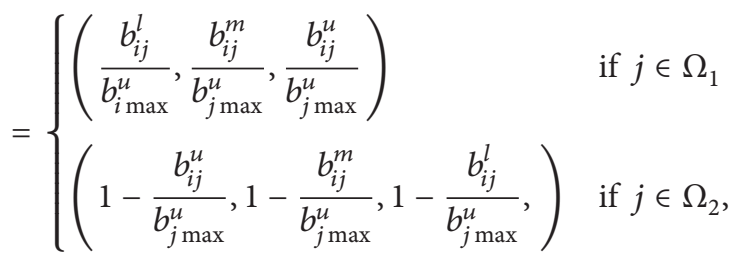

where $b_{j \max }^{u}=\max _{\forall i}\left\{b_{i j}^{u} \mid i=1,2, \ldots, m\right\}$.

For an interval fuzzy number $\widehat{h}_{i j}=\left[h_{i j}^{l}, h_{i j}^{u}\right]$, it can be normalized as follows [9]:

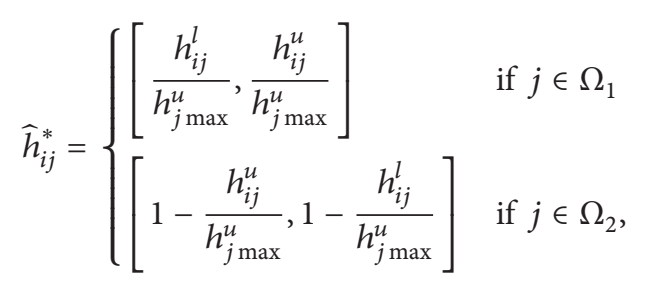

where $h_{j \max }^{u}=\max _{\forall i}\left\{h_{i j}^{u} \mid i=1,2, \ldots, m\right\}$.

For a real number $g_{i j}$, it can be normalized as follows [9]:

$$
g_{i j}^{*}= \begin{cases}\frac{g_{i j}}{g_{i \max }} & \text { if } j \in \Omega_{1} \\ 1-\frac{g_{i j}}{g_{i \max }} & \text { if } j \in \Omega_{2},\end{cases}
$$

where $g_{j \max }=\max _{\forall i}\left\{g_{i j} \mid i=1,2, \ldots, m\right\}$.

2.3.2. Transformation of Normalization Data Size into BLTS. For convenience, $u_{N}(x)$ is hereafter employed to express the membership function of the triangular, interval, and real numbers. Letting $F\left(\mathbf{S}_{H}\right)$ be the set of fuzzy sets defined in $\mathbf{S}_{H}$, the BLTS, $u_{N}(x)$ is transformed into $F\left(\mathbf{S}_{H}\right)$ using the function $\tau_{N S_{H}}[17]:$

$$
\begin{aligned}
\tau_{N S_{H}}: f_{i j}^{*} & \longrightarrow F\left(\mathbf{S}_{H}\right), \\
\tau_{N S_{H}}\left(f_{i j}^{*}\right) & =\left\{\left(s_{k}^{\prime}, \gamma_{k}^{N}\right) \mid k \in\{0,1, \ldots, H\},\right. \\
\gamma_{k}^{N} & =\max _{\forall x} \min \left\{u_{N}(x), u_{s_{k}}(x)\right\} .
\end{aligned}
$$

Note that $\gamma_{k}^{N}$ is not related to $a_{k}^{\prime}$ at all but represents the extent to which $u_{N}(x)$ belongs to fuzzy linguistic term $s_{k}^{\prime}$. Supposing the BLTS is $S^{7}=\left(s_{0}^{\prime}, s_{1}^{\prime}, \ldots, s_{k}^{\prime}, \ldots, s_{6}^{\prime}\right)$ with membership function of triangular fuzzy numbers $u_{s_{k}^{\prime}}(x)$ defined as $u_{s_{k}^{\prime}}(x)=\left(b_{k}^{l}, b_{k}^{m}, b_{k}^{u}\right)=(\max \{(k-1) / 7,0\}, k / 7, \min \{(k+$ 1) $/ 7,1\})(k=0,1, \ldots, 6)$, the transformations of a triangular fuzzy number, an interval number, and a real number into the linguistic terms are illustrated, respectively, in Figures 1-3.

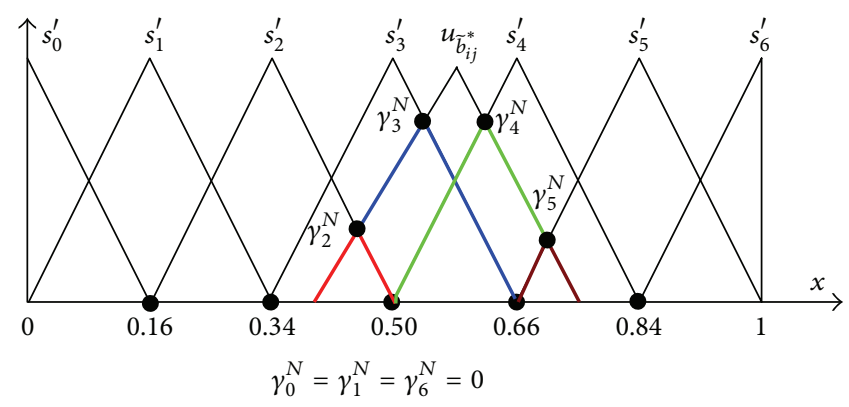

FIGURE 1: Illustration of transforming a triangular number to a linguistic term in BLTS.

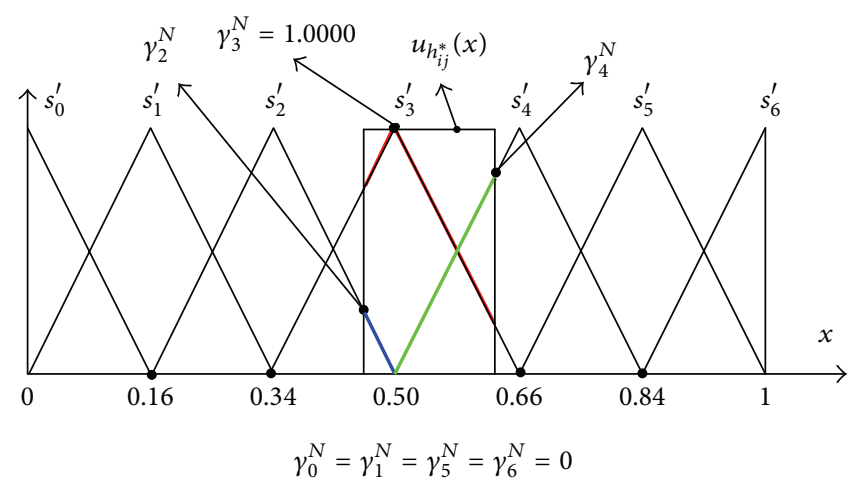

FIGURE 2: Illustration of transforming an interval to a linguistic term in the BLTS.

2.3.3. Transformation of $F\left(\mathbf{S}_{H}\right)$ into a 2-Tuple Linguistic Representation. $F\left(\mathbf{S}_{H}\right)$ is transformed into a 2-tuple linguistic representation using the following equation [17]:

$$
\begin{aligned}
\chi: F\left(\mathbf{S}_{H}\right) & \longrightarrow[0, H], \\
\chi\left(F\left(\mathbf{S}_{H}\right)\right) & =\chi\left(\left\{\left(s_{k}^{\prime}, \gamma_{k}^{N}\right), k=0,1, \ldots, H\right\}\right) \\
& =\frac{\sum_{k=0}^{H} k \gamma_{k}^{N}}{\sum_{k=0}^{H} \gamma_{k}^{N}}=\beta, \\
r_{i j} & =\left(s_{l}^{\prime}, a_{l}^{\prime}\right)=\Delta\left(\chi\left(F\left(\mathbf{S}_{H}\right)\right)\right)=\Delta(\beta) .
\end{aligned}
$$

\section{Fuzzy Measures}

\subsection{Basic Concepts}

Definition 1 (see [18]). Let $P(C)$ be the power set of $C=$ $\left\{c_{1}, c_{2}, \ldots, c_{j}, \ldots, c_{n}\right\}$; a discrete fuzzy measure on $P(C)$ is a set function $\mu: P(C) \rightarrow[0,1]$, satisfying the following conditions:

(i) boundedness: $\mu(\phi)=0, \mu(C)=1$;

(ii) monotonicity: if $B_{1}, B_{2} \in P(C)$, and $B_{1} \subseteq B_{2}$ then $\mu\left(B_{1}\right) \leq \mu\left(B_{2}\right)$.

From the perspective of MADM, $\mu\left(B_{1}\right)$ represents the strength of coalition of $B_{1}$. Intuitively, we could get the 


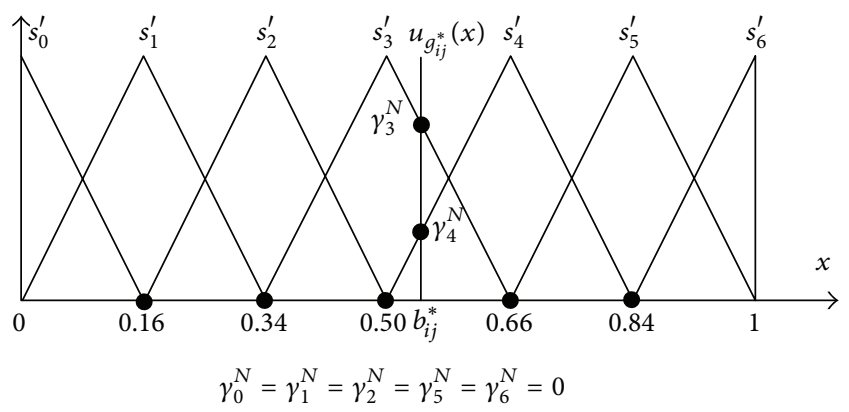

FIGURE 3: Illustration of transforming a real number to a linguistic term in the BLTS.

following results about any coalition $B_{1}, B_{2} \in P(C), B_{1} \cap B_{2}=$ $\phi$ : If $\mu\left(B_{1}\right)+\mu\left(B_{2}\right)<\mu\left(B_{1} \cup B_{2}\right), B_{1}$ and $B_{2}$ exhibit a negative synergetic interaction between them; if $\mu\left(B_{1}\right)+\mu\left(B_{2}\right)>$ $\mu\left(B_{1} \cup B_{2}\right), B_{1}$ and $B_{2}$ exhibit a positive synergetic interaction between them; and if $\mu\left(B_{1}\right)+\mu\left(B_{2}\right)=\mu\left(B_{1} \cup B_{2}\right), B_{1}$ and $B_{2}$ are considered to be independent, which is also called an additive measure. In order to avoid heavy notations, hereafter, we denote $\mu\left(\left\{c_{i}, \ldots, c_{k}\right\}\right), \mu\left(T \cup\left\{c_{i}, c_{j}\right\}\right), I\left(\left\{c_{i}, \ldots, c_{k}\right\}\right)$, and $m_{v}\left(\left\{c_{i}, \ldots, c_{k}\right\}\right)$, respectively, with $\mu(i \cdots k), \mu(T i j), I(i \cdots k)$, and $m_{v}(i \cdots k)$.

Although fuzzy measures constitute a flexible tool for modeling the importance of coalitions, they are not easy to handle in a practical problem, since we generally need to find $2^{n}-2$ values for $n$ criteria. In most of the practical problems, an expert can guess the importance of singletons, or of pairs of elements, but not that of subsets of more elements. So in this paper, 2-additive fuzzy measure was used to identify fuzzy measures, which coincides with habits of thought and is a better trade-off between modeling accuracy and algorithm complexity, for only $n(n+1) / 2$ real coefficients are required to define a 2 -additive fuzzy measure.

Definition 2 (see [19]). Let $\mu$ be a fuzzy measure on $P(C)$. The Shapley value for every $c_{j}$ is defined as

$$
I(j)=\sum_{T \subseteq C \mid c_{j}} \frac{(n-|T|-1) !|T| !}{n !}[\mu(T j)-\mu(T)]
$$

where $|\cdot|$ denotes the cardinality of a set. $I(j)$ can be interpreted as the importance of element $c_{j}$ with regard to interactions. A basic property of $I(j)$ is $\sum_{j=1}^{n} I(j)=\mu(C)=1$, and if the relationship of all attributes exhibits independence, then $I(j)=\mu(j)$.

\subsection{Two-Additive Fuzzy Measures}

Definition 3 (see [19]). Set function $m_{v}(B)(B \in P(C))$, is called Möbius representation, and the relationship between the Möbius representation and fuzzy measure is

$$
M_{v}(B)=\sum_{T \subseteq B}(-1)^{|B|-|T|} \mu(T), \quad \forall B \in P(C) .
$$

Inversely, for a given Möbius representation, the corresponding fuzzy measure can be calculated as follows:

$$
\mu(T)=\sum_{B \subseteq T} m_{v}(B) .
$$

For any coalition $T \in P(C)$ and $|T|>k, m_{v}(T)=0$, and there exists at least one $T(|T|=k)$, while $m_{v}(T) \neq 0$, which we call $k$-order additive fuzzy measure. Obviously, if $k=n$, the fuzzy measure is a general fuzzy measure; if $k=2$, then we call it 2-order fuzzy measure; and if $k=1$, then it reduces to an additive measure. According to (12) and (13), we have $\mu(j)=m_{v}(j), m_{v}(\phi)=\mu(\phi)=0$.

\subsection{From Möbius to Interaction Index}

Definition 4 (see [19]). For a given Möbius representation, the corresponding interaction index can be calculated as

$$
I(T)=\sum_{k=0}^{n-|T|} \frac{1}{k+1} \sum_{\substack{B \subseteq C|T\\| B \mid=k}} m_{v}(T \cup B),
$$

where $C \backslash T$ is the set difference between $C$ and $T$. For the 2-order fuzzy measure, we can obtain the following results:

$$
m_{v}(i)=I(i)-\frac{1}{2} \sum_{j \in C \backslash i} I(i j), \quad I(i j)=m_{v}(i j) .
$$

The relationship of $c_{i}, c_{j}$ exhibits a positive synergetic interaction, then $I(i j)>0$, and the stronger the positive synergetic interaction, the greater the value of $I(i j)$. If it exhibits a negative synergetic interaction, then $I(i j)<0$. If it is considered to be independence, then $I(i j)=0$.

\subsection{Entropy of Fuzzy Measure}

Definition 5 (see [20]). For coalition $C=\left\{c_{1}, c_{2}, \ldots, c_{j}\right.$, $\left.\ldots, c_{n}\right\}$, the entropy of fuzzy measure is defined as

$$
H_{M}(\mu)=\sum_{j=1}^{n} \sum_{B \subseteq C \mid c_{j}} \gamma_{B}(|C|) \psi[\mu(B j)-\mu(B)],
$$

where $\psi(x)=-x \ln x, \gamma_{B}(|C|)=(|C|-|B|-1) !|B| ! /|C| !, \forall B \epsilon$ $P(C)$, and $\sum_{B \subseteq C \mid c_{j}} \gamma_{B}(|C|)=1$.

According to (16), $\mu(B j)-\mu(B)=\sum_{T \subseteq B \cup j} m_{v}(T)-$ $\sum_{T \subseteq B} m_{v}(T)=\sum_{T \subseteq B} m_{v}(T \cup j)$, and for 2-additive fuzzy measure, $\sum_{T \subseteq B} m_{v}(T \cup j)$ can be simplified as $\sum_{T \subseteq B} m_{v}(T \cup$ $j)=m_{v}(j)+\sum_{i \in B} m_{v}(i j)$, and substituting (15) into $m_{v}(j)+$ $\sum_{i \in B} m_{v}(i j)$, then $\mu(B j)-\mu(B)$ can be further simplified as

$$
\mu(B j)-\mu(B)=I(j)-\frac{1}{2} \sum_{i \in C \backslash B} I(i j)+\frac{1}{2} \sum_{i \in B} I(i j) .
$$

Compared with (16), (17) is the special case under the conditions of 2-order fuzzy measure, more convenient and easier to use. 


\subsection{Procedures to Identify 2-Additive Fuzzy Measure Based on the Maximum Entropy}

Step 1 (identifying Shapley values). Since the sum of all attributes' Shapley values satisfies $\sum_{j=1}^{n} I(j)=1$, it is reasonable to consider the Shapley values as the weights with no regard to dependence. AHP, the most widely used approach to identify weights, is employed here, and for its calculation procedure, one can refer to [21].

Step 2 (determining the range of $I(i j))$. According to the literature [22], $\forall\{i, j\} \in C$, if $|I(i j)|=t_{i j} \leq 2 \min \{I(i), I(j)\} /(n-1)$, then the nonnegativity of fuzzy measures can be ensured. As such, the interaction index $I(i j)$ should be limited to $\left[-t_{i j}, t_{i j}\right]$. In this paper $\left[-t_{i j}, t_{i j}\right]$ was evenly divided into five parts: $\left[0.6 t_{i j}, t_{i j}\right],\left[0.2 t_{i j}, 0.6 t_{i j}\right],\left[-0.2 t_{i j}, 0.2 t_{i j}\right],\left[-0.6 t_{i j},-0.2 t_{i j}\right]$, and $\left[-t_{i j},-0.6 t_{i j}\right]$, which, respectively, represent the five types of interactions: significantly positive synergetic interaction, positive synergetic interaction, independence, negative synergetic interaction, and significantly negative synergetic interaction. According to decision makers' cognition on the interaction of any two attributes, they determine one type of interaction and the corresponding range of $I(i j)$.

Step 3. Determine $I(i j)$ by solving the following optimization model:

$$
\begin{array}{ll}
\max & H_{M}(\mu) \\
& =\sum_{j=1}^{n} \sum_{B \subseteq C \backslash c_{j}} \gamma_{B}(|C|) \psi\left[I(j)-\frac{1}{2} \sum_{i \in C \backslash B} I(i j)+\frac{1}{2} \sum_{i \in B} I(i j)\right] \\
\text { s.t. } & I(i j) \in\left[-t_{i j}, t_{i j}\right] \\
& I(j)=\omega_{j} \\
& i, j=1,2, \ldots, n, i \neq j .
\end{array}
$$

Step 4. Determine $\mu(j)$ in accordance with (15).

\section{Linguistic Aggregation Operators with Interaction}

Up to now, many aggregation operators have been developed to aggregate linguistic ratings, as linguistic ordered weighted geometric averaging operator [23], extended 2tuple weighted geometric operator [24], and so forth. However, most of the existent linguistic aggregation operators only consider the addition of the importance of individual attributes, that is, presupposing the relationships of all attributes are independent. Based on the basic Choquet integrals [14], this paper develops the operators considering the interactions between attributes.

Definition 6. Linguistic weighted geometric averaging with interaction (LWGAI) operator of dimension $n$ is a mapping
LWGAI: $\mathbf{S}^{n} \rightarrow \mathbf{S}$, which is defined as

$$
\begin{aligned}
\left(s_{k}, a_{k}\right) & =\operatorname{LWGAI}\left(\left(s_{1}, a_{1}\right),\left(s_{2}, a_{2}\right), \ldots,\left(s_{n}, a_{n}\right)\right) \\
& =\Delta\left(\prod_{j=1}^{n} f\left(c_{(j)}\right)^{\left[\mu\left(C_{(j)}\right)-\mu\left(C_{(j-1)}\right)\right]}\right),
\end{aligned}
$$

where $f\left(c_{(j)}\right)$ is the reordering of $\left\{f\left(c_{1}\right), f\left(c_{2}\right), \ldots, f\left(c_{j}\right)\right.$, $\left.\ldots, f\left(c_{n}\right)\right\}$ with $f\left(c_{j}\right)=\Delta^{-1}\left(s_{j}, a_{j}\right)(j=1,2, \ldots, n)$ such that $f\left(c_{(1)}\right) \geq f\left(c_{(2)}\right) \geq \cdots \geq f\left(c_{(n)}\right), C_{(j)}=\left(c_{(1)}, c_{(2)}, \ldots, c_{(j)}\right)$, $f\left(c_{(n+1)}\right)=0$, and $\mu\left(C_{(0)}\right)=0$ :

(1) If all the elements in $C$ are independent, then $\mu\left(C_{(j)}\right)-$ $\mu\left(C_{(j-1)}\right)=\mu\left(c_{(j)}\right),\left(s_{k}, a_{k}\right)=\operatorname{LWGAI}(\cdot)=$ $\Delta\left(\prod_{j=1}^{n} f\left(c_{(j)}\right)^{\mu\left(c_{(j)}\right)}\right)=\Delta\left(\prod_{j=1}^{n} f\left(c_{j}\right)^{\mu\left(c_{j}\right)}\right)$, and since $\mu(C)=\sum_{j=1}^{n} \mu\left(c_{j}\right)=1, \mu\left(c_{j}\right)$ can be considered equal to $\omega_{j}$, the weight of the attribute $c_{j}$. In this situation, the LWGAI operator is reduced to linguistic weighted geometric averaging (LWGA) operator and can conversely be considered the extension of LWGA operator with regard to interactions.

(2) According to (13), for 2-additive fuzzy measure, $\mu\left(C_{(j)}\right)-\mu\left(C_{(j-1)}\right)$ can be transformed into $m_{v}\left(c_{(j)}\right)+$ $\sum_{j_{1}=1}^{j-1} m_{v}\left(c_{(j)}, c_{\left(j_{1}\right)}\right)$, and for the convenience of computation (19) can be transformed into $\operatorname{LWGAI}(\cdot)=$ $\Delta\left(\prod_{j=1}^{n} f\left(c_{(j)}\right)^{\left[m_{v}\left(c_{(j)}\right)+\sum_{j_{1}=1}^{j-1} m_{v}\left(c_{(j)}, c_{\left(j_{1}\right)}\right)\right]}\right)$, which further according to (15) can be transformed into

$$
\operatorname{LWGAI}(\cdot)=\Delta\left(\prod_{j=1}^{n} f\left(c_{(j)}\right)^{\left[\mu\left(c_{(j)}\right)+\sum_{j_{1}=1}^{j-1} I\left(c_{(j)}, c_{\left(j_{1}\right)}\right)\right]}\right),
$$

where $I\left(c_{(j)}, c_{\left(j_{1}\right)}\right)$ has been calculated by the optimization model (18).

In $(20), \mu\left(C_{(j)}\right)-\mu\left(C_{(j-1)}\right)$ can be considered actually weighting the rating of attribute $c_{(j)}$ itself. In group decision making different decision makers maybe provide different ratings to the identical attributes, especially to the qualitative ones, with some ratings unduly high but some ones unduly low. Therefore in the process of integrating the individual experts' ratings into the collective one, we should not only assign weights to the ratings themselves to embody experts' authority, but assign weights to the ordered positions of ratings to mitigate the influence of unfair ratings on the decision results by weighting these ratings with small values. With this consideration, we develop the following operator.

Definition 7. Linguistic hybrid weighted geometric averaging with interaction (LHWGAI) operator of dimension $n$ is a mapping LHWGAI: $\mathbf{S}^{n} \rightarrow \mathbf{S}$, which is defined as

$$
\begin{aligned}
\left(s_{k}, a_{k}\right) & =\operatorname{LHWGAI}\left(\left(s_{1}, a_{1}\right),\left(s_{2}, a_{2}\right), \ldots,\left(s_{n}, a_{n}\right)\right) \\
& =\Delta\left(\prod_{j=1}^{n} \phi\left(c_{(j)}\right)^{\left[\mu\left(C_{(j)}\right)-\mu\left(C_{(j-1)}\right)\right]}\right),
\end{aligned}
$$


where $\phi\left(c_{(j)}\right)$ is the reordering of $\left\{\phi\left(c_{1}\right), \phi\left(c_{2}\right), \ldots, \phi\left(c_{j}\right)\right.$, $\left.\ldots, \phi\left(c_{n}\right)\right\}$ with $\phi\left(c_{j}\right)=\Delta^{-1}\left(s_{j}, a_{j}\right)^{n \times \rho_{j}}(j=1,2, \ldots, n)$, such that $\phi\left(c_{(1)}\right) \geq \phi\left(c_{(2)}\right) \geq \cdots \geq \phi\left(c_{(n)}\right)$. In $\phi\left(c_{j}\right), \rho_{j}$ is used to weight the ordered position of rating of attribute $c_{j}$ with $\rho_{j} \in[0,1]$, and $\sum_{j=1}^{n} \rho_{j}=1$, and $n$ is the balancing coefficient:

(1) If $\boldsymbol{\rho}=(1 / n, 1 / n, \ldots, 1 / n)$, then $\phi\left(c_{j}\right)=\Delta^{-1}\left(s_{j}\right.$, $\left.a_{j}\right)^{n \times 1 / n}=\Delta^{-1}\left(s_{j}, a_{j}\right)=f\left(c_{j}\right)$. Therefore, the LWGAI operator is a special case of the LHWGAI, which reflects not only the importance degree of the given ratings of an attribute but also their ordered positions.

(2) According to normal distribution, the further a value is apart from the mean value, the smaller the value of its probability density function is, while the closer a value is to the mean value, the greater the value of its probability density function is, which coincides with notion mentioned above. Therefore the following formula is employed to determine the weights to weight the ordered position of the rating of attribute $c_{j}[25]$ :

$$
\begin{array}{r}
\rho_{j}=\frac{\exp \left(-\left(\Delta^{-1}\left(s_{j}, a_{j}\right)-\bar{q}_{j}\right)^{2} / 2 \sigma_{n}^{2}\right)}{\sum_{j=1}^{n} \exp \left(-\left(\Delta^{-1}\left(s_{j}, a_{j}\right)-\bar{q}_{j}\right)^{2} / 2 \sigma_{n}^{2}\right)} \\
\quad j=1,2, \ldots, n,
\end{array}
$$

where $\bar{q}_{j}=(1 / n) \sum_{j=1}^{n} \Delta^{-1}\left(s_{j}, a_{j}\right)$ is the mean value of $\Delta^{-1}\left(s_{j}, a_{j}\right)(j=1,2, \ldots, n)$ and $\sigma_{n}=$ $\sqrt{(1 /(n-1)) \sum_{j=1}^{n}\left(\Delta^{-1}\left(s_{j}, a_{j}\right)-\bar{q}_{j}\right)^{2}}$, the standard deviation.

\section{Applications to Selection of Phase Change Materials}

Taking full advantage of solar power is one of the most important means to mitigate energy shortages, resource depletion, environmental pollution, and so forth, brought about by traditionally thermal power generation, but due to day alternating with night, climate change, and solar energy radiation intensity fluctuating with time within a day, solar energy is an intermittent, not a stable, energy source. Consequently, integration of the solar power with thermal energy storage (TES) is necessary for its effective utilization, as it can store solar power and release it whenever necessary, resulting in capacity buffer, stable power output, and increased annual utilization rate. There are three types of TES: sensible heat storage, phase change heat storage (latent heat storage), and thermochemical energy storage [2]. Of the three types, phase change heat storage can store and release heat with almost no change in temperature and enjoys the following good properties: stable output temperature and energy and greater density in heat storage. There are a large number of phase change materials available to designers, who, when selecting materials, are required to take into account a large number of material selection criteria depending on the applications, and the performance of phase change materials directly influences the performance and cost of TES. As such, it is a complex, time consuming, yet urgent problem to select the suitable phase change materials for use in a particular kind of TES applications. Figure 4 illustrates the procedure for phase change material selection.

5.1. Identifying the Evaluating Criteria and Raw Data. Generally, analyzing and translating the design requirements (expressed as constraints and objectives) into required material's properties (attributes) is the first step, and then we divide the required material properties into "rigid" and "soft" requirements. Any material with one property that cannot satisfy the "rigid" requirements can first be eliminated. Hightemperature molten salt and aluminum-base alloy are two kinds of the most potential phase change materials, but the high-temperature molten salt suffers from lower thermal conductivity and solid-liquid delamination, and it is eliminated from the candidates not satisfying the design requirements and constraints. The five kinds of aluminum-base alloy are listed as the candidate materials, that is, $35 \mathrm{Mg} / 6 \mathrm{Zn}\left(o_{1}\right)$, $33.2 \mathrm{Cu}\left(o_{2}\right), 12 \mathrm{Si}\left(o_{3}\right), 5 \mathrm{Si} / 30 \mathrm{Cu}\left(o_{4}\right)$, and $34 \mathrm{Mg}\left(o_{5}\right)$, in which the number in front of an elemental symbol expresses the percentage of the corresponding elemental symbol. The ratings of the primary selection materials against any attribute are checked, and the attributes with much less distinction degree, though they may be important, can be removed since they have little effect on the final ranking results. As a result, the six attributes $\left(c_{1}\right.$ : economies, $c_{2}$ : chemical stability, $c_{3}$ : phase change latent heat, $c_{4}$ : density, $c_{5}$ : thermal conductivity, and $c_{6}$ : corrosivity) employed to material ranking are listed in Table 1, in which the criteria's types, expressions, and requirements are also described. Listed in Table 2 are the raw ratings $f_{i j}^{t}$, the rating of alternative $o_{i}$ in respect of attribute $c_{j}$ provided by expert $e_{t}$.

5.2. Transforming Heterogeneous Information into Linguistic Terms in BLTS. In this paper, suppose the BLTS is $S^{7}=$ $\left(s_{0}^{\prime}, s_{1}^{\prime}, \ldots, s_{k}^{\prime}, \ldots, s_{6}^{\prime}\right)$. For ratings of attribute price $\left(c_{4}\right)$ with real values, according to (8), compute $u_{g_{i 4}^{*}}(x)$; for ratings of attribute $c_{3}$ with interval values, according to (7), compute $u_{\widehat{h}_{i 3}^{*}}(x)$; and for ratings of attribute $c_{5}$ with triangular fuzzy numbers, according to (6), compute $u_{\tilde{b}_{i 5}^{*}}(x)$. Subsequently, according to (9), compute $\gamma_{k}^{N}(k=0,1, \ldots, 6)$, and finally according to (10) compute $\left(s_{l}^{\prime}, a_{l}^{\prime}\right)$. For ratings of attributes $c_{1}, c_{2}$, and $c_{6}$, which are linguistic terms with different cardinalities, according to (3), make the linguistic terms uniformed. Table 3 shows the normalized calculation results.

\subsection{Integrating the Individual Ratings of Each Expert}

5.3.1. Identifying the Expert Shapley Values. Since $\sum_{t=1}^{4} I_{e}(t)=$ $1, I_{e}(t)$ is equivalent to the corresponding weight $\omega_{e}(t)$ with no regard to interactions. Suppose $\mathbf{I}_{e}, \mathbf{I}_{e}=\left(I_{e}(1), I_{e}(2)\right.$, $\left.I_{e}(3), I_{e}(4)\right)=(0.2220,0.2040,0.2860,0.2880)$, was calculated using AHP. 


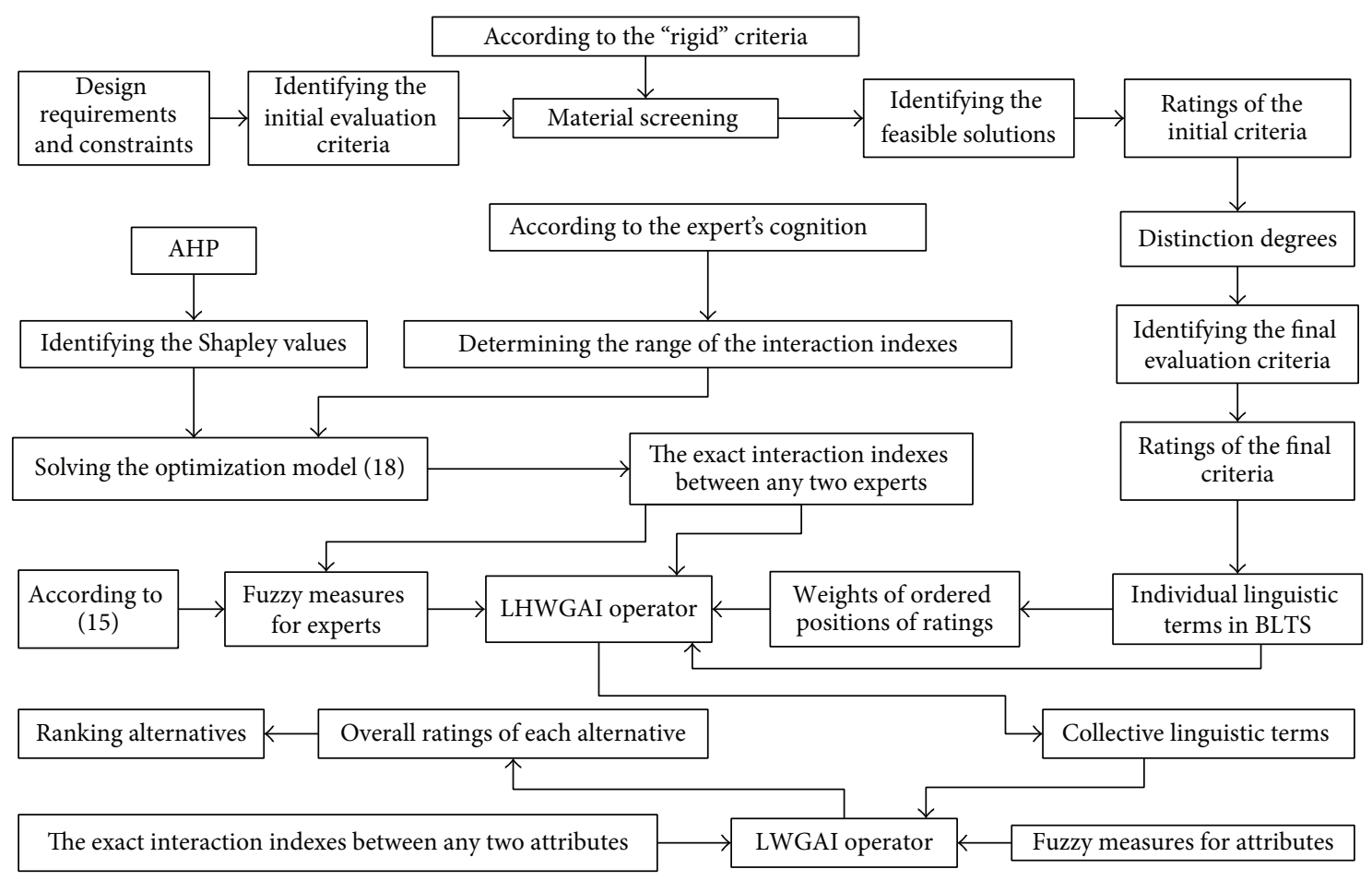

FIGURE 4: Procedure for phase change material selection.

TABLE 1: Criteria's types, expressions, and requirements.

\begin{tabular}{|c|c|c|c|}
\hline Criteria & Types & Expressions & Requirements \\
\hline$c_{1}:$ economies & Cost & Linguistic terms & $\begin{array}{l}\text { The less the ratings, the better the attributes. The ratings of material cost, } \\
\text { subject to various factors, are hardly exactly identified and so expressed } \\
\text { in linguistic terms according to the knowledge of experts. }\end{array}$ \\
\hline$c_{2}:$ chemical stability & Beneficial & Linguistic terms & $\begin{array}{l}\text { Materials with good chemical stability, though subject to repeated heat } \\
\text { absorption and heat release, do not experience the problems of } \\
\text { segregation, side reaction, and chemolysis and hence smaller attenuation } \\
\text { in the heat storage capacity. }\end{array}$ \\
\hline$c_{3}:$ phase change latent heat & Beneficial & Intervals & $\begin{array}{l}\text { Under the same phase change temperature, the greater the phase change } \\
\text { latent heat is, the more the energy can be stored. }\end{array}$ \\
\hline$c_{4}:$ density & Beneficial & Exact values & $\begin{array}{l}\text { For the materials with approximately equal phase change latent heat, the } \\
\text { greater the density is, the greater the heat per volume can be stored, } \\
\text { which lowers the cost of the heat storage equipment. }\end{array}$ \\
\hline$c_{5}:$ thermal conductivity & Beneficial & Triangular values & $\begin{array}{l}\text { Greater thermal conductivity implies quicker speed in the process of heat } \\
\text { storage and extraction and better performance in conductivity, and that } \\
\text { absorbing or releasing the same heat requires less temperature gradient. }\end{array}$ \\
\hline$c_{6}:$ corrosivity & Cost & Linguistic terms & $\begin{array}{l}\text { Materials with smaller high-temperature corrosivity are compatible with } \\
\text { many other materials, which implies a wide range of material selection } \\
\text { for the heat storage pieces of equipment, lowering their cost. }\end{array}$ \\
\hline
\end{tabular}

5.3.2. Identifying the Interaction Indexes between Experts and Their Fuzzy Measures. Since the expert preferences are related to expert's social status, prestige, knowledge structures, expectations, and so forth, consequently in group decision making, the preferences among experts maybe exhibit interactions. If these respects of experts are similar, the relationship of experts exhibits a negative synergetic interaction, resulting in overestimation if neglected, while if they are greatly different, it exhibits a positive synergetic interaction, resulting in underestimation if neglected. Determine the range of the interaction indexes $\left[-t_{i j}, t_{i j}\right]$ between experts as shown in Table 4 . By solving the optimization model (18), the interaction indexes can be obtained: $I_{e}^{*}(12)=$ $-0.0272, I_{e}^{*}(13)=0.0296, I_{e}^{*}(14)=-0.0080, I_{e}^{*}(23)=$ $-0.0117, I_{e}^{*}(24)=0.0272$, and $I_{e}^{*}(34)=0.0381$. According to (15), determine the single expert's Möbius representation; for example, $m_{v e}(1)=I_{e}(1)-0.5 \times\left(I_{e}^{*}(12)+I_{e}^{*}(13)+I_{e}^{*}(14)\right)=$ $0.2220-0.5 \times(-0.0272+0.0296-0.0080)=0.2228$, and 
TABLE 2: Raw ratings on each attribute with respect to each alternative and each expert.

\begin{tabular}{|c|c|c|c|c|c|c|}
\hline PCMs & $\begin{array}{l}c_{1} \\
f_{i 1}^{t}\end{array}$ & $\begin{array}{l}c_{2} \\
f_{i 2}^{t}\end{array}$ & $\begin{array}{c}c_{3} \mathrm{~kJ} / \mathrm{kg} \\
f_{i 3}^{t}\end{array}$ & $\begin{array}{c}c_{4} \mathrm{~kg} / \mathrm{m}^{3} \\
f_{i 4}^{t}\end{array}$ & $\begin{array}{c}c_{5} \mathrm{~W} /(\mathrm{m} \cdot \mathrm{K}) \\
f_{i 5}^{t}\end{array}$ & $\begin{array}{l}c_{6} \\
f_{i 6}^{t} \\
\end{array}$ \\
\hline \multicolumn{7}{|c|}{ Expert 1} \\
\hline$o_{1}$ & $s_{2}^{5}$ & $s_{1}^{5}$ & {$[300,320]$} & 2380 & {$[170,190,220]$} & $s_{2}^{3}$ \\
\hline$o_{2}$ & $s_{4}^{5}$ & $s_{3}^{5}$ & {$[340,355]$} & 3424 & {$[105,130,155]$} & $s_{1}^{3}$ \\
\hline$o_{3}$ & $s_{1}^{5}$ & $s_{2}^{5}$ & {$[540,570]$} & 2700 & {$[120,155,180]$} & $s_{1}^{3}$ \\
\hline$o_{4}$ & $s_{4}^{5}$ & $s_{4}^{5}$ & {$[400,430]$} & 2730 & {$[160,175,205]$} & $s_{2}^{3}$ \\
\hline$o_{5}$ & $s_{3}^{5}$ & $\begin{array}{l}s_{1}^{5} \\
s_{1}^{5}\end{array}$ & {$[310,350]$} & 2300 & {$[175,205,225]$} & $s_{1}^{3}$ \\
\hline \multicolumn{7}{|c|}{ Expert 2} \\
\hline$o_{1}$ & $s_{2}^{7}$ & $s_{2}^{7}$ & {$[290,310]$} & 2380 & {$[165,190,225]$} & $s_{3}^{7}$ \\
\hline$o_{2}$ & $s_{5}^{7}$ & $s_{4}^{7}$ & {$[320,340]$} & 3424 & {$[95,130,145]$} & $s_{5}^{7}$ \\
\hline$o_{3}$ & $s_{2}^{7}$ & $s_{3}^{7}$ & {$[480,530]$} & 2700 & {$[110,145,185]$} & $s_{4}^{7}$ \\
\hline$o_{4}$ & $s_{4}^{7}$ & $s_{2}^{7}$ & {$[380,420]$} & 2730 & {$[155,185,210]$} & $s_{2}^{7}$ \\
\hline$o_{5}$ & $s_{6}^{7}$ & $s_{6}^{7}$ & {$[300,340]$} & 2300 & {$[185,210,230]$} & $s_{6}^{7}$ \\
\hline \multicolumn{7}{|c|}{ Expert 3} \\
\hline$o_{1}$ & $s_{4}^{5}$ & $s_{2}^{7}$ & {$[310,330]$} & 2380 & {$[145,175,210]$} & $s_{2}^{5}$ \\
\hline $\mathrm{O}_{2}$ & $s_{4}^{5}$ & $s_{6}^{7}$ & {$[350,370]$} & 3424 & {$[105,130,160]$} & $s_{1}^{5}$ \\
\hline$o_{3}$ & $s_{2}^{5}$ & $s_{3}^{7}$ & {$[470,490]$} & 2700 & {$[115,125,150]$} & $s_{3}^{5}$ \\
\hline$o_{4}$ & $s_{1}^{5}$ & $s_{2}^{7}$ & {$[420,450]$} & 2730 & {$[165,190,220]$} & $s_{4}^{5}$ \\
\hline$o_{5}$ & $s_{3}^{5}$ & $s_{4}^{7}$ & {$[305,355]$} & 2300 & {$[155,195,210]$} & $s_{3}^{5}$ \\
\hline \multicolumn{7}{|c|}{ Expert 4} \\
\hline$o_{1}$ & $s_{5}^{7}$ & $s_{2}^{3}$ & {$[305,350]$} & 2380 & {$[157,176,205]$} & $s_{1}^{5}$ \\
\hline $\mathrm{o}_{2}$ & $s_{6}^{7}$ & $s_{1}^{3}$ & {$[330,370]$} & 3424 & {$[105,125,150]$} & $s_{4}^{5}$ \\
\hline$o_{3}$ & $s_{3}^{7}$ & $s_{1}^{3}$ & {$[445,480]$} & 2700 & {$[118,135,165]$} & $s_{2}^{5}$ \\
\hline$o_{4}$ & $s_{2}^{7}$ & $s_{2}^{3}$ & {$[430,460]$} & 2730 & {$[158,205,238]$} & $s_{1}^{5}$ \\
\hline$o_{5}$ & $s_{4}^{7}$ & $s_{1}^{3}$ & {$[335,350]$} & 2300 & {$[165,208,235]$} & $s_{3}^{5}$ \\
\hline
\end{tabular}

according to (13), $\mu_{e}(1)=m_{v e}(1)=0.2228$. Similarly, $\mu_{e}(2)=$ $0.2098, \mu_{e}(3)=0.2580$, and $\mu_{e}(4)=0.2593$.

5.3.3. Calculating the Collective Ratings. For the attribute $c_{4}$, since the 4 experts provide the same ratings on each alternative, the individual ratings are also the collective ratings. For the attributes $c_{1}, c_{2}, c_{3}, c_{5}$, and $c_{6}$, respectively, according to (22), calculate, respectively, for the five alternatives the weight vectors $(\rho)$ of ordered position of individual expert's ratings. The number of these ordered position weight vectors amounts to 25. According to Definition 7, calculate the collective ratings $r_{i j}$ shown in the bottom of Table 3 .

5.4. Calculating the Overall Ratings of Each Alternative. With the same method used in identifying each expert's Shapley values, we can obtain the attribute's Shapley values as $\mathbf{I}_{c}=\left(I_{c}(1), I_{c}(2), I_{c}(3), I_{c}(4), I_{c}(5), I_{c}(6)\right)=$ $(0.2076,0.3170,0.1225,0.1549,0.1011,0.0968)$ and the fuzzy measure of attributes as $\mu_{c}(1)=0.1773, \mu_{c}(2)=0.3212$, $\mu_{c}(3)=0.1122, \mu_{c}(4)=0.1402, \mu_{c}(5)=0.0878$, and $\mu_{c}(6)=0.0917$. According to Definition 6, the overall ratings of each alternative $z_{i}$ are calculated as $z_{1}=3.1116$, $z_{2}=4.2852, z_{3}=3.3714, z_{4}=3.5565$, and $z_{5}=4.0654$. In the light of the results, the best material is $o_{2}(33.2 \mathrm{Cu})$, followed successively by $o_{5}, o_{4}, o_{3}$, and $o_{1}$.

\section{Conclusions}

(1) This study has contributed to the material selection literature by (i) considering hybrid information, including real values, interval values, triangular fuzzy numbers, and linguistic variables with different cardinalities, and proposing a method to transform the heterogeneous information to linguistic terms in the BLTS; (ii) providing a feasible and effective method to determine 2-additive fuzzy measures based on the principle of maximum entropy and further simplifying the expressions of Marichal entropy and Choquet integral which, after simplification, is more convenient to use in practice; and (iii) proposing the LHWGAI operator considering not only the interactions between attributes but the ordered positions of the attribute ratings.

(2) Compared with [26], in which the interaction index is elicited according directly to expert's cognition, lacking any objective basis, however, in this paper, first merely identify the range of it according to expert's cognition and then further determine its exact value according to the principle of maximum entropy, embodying the expert's cognition and enjoying the good objectiveness. 
TABLE 3: Individual and corrective normalized ratings.

\begin{tabular}{|c|c|c|c|c|c|c|}
\hline PCMs & $\begin{array}{l}c_{1} \\
r_{i 1}^{t} \\
\end{array}$ & $\begin{array}{l}c_{2} \\
r_{i 2}^{t} \\
\end{array}$ & $\begin{array}{l}c_{3} \\
r_{i 3}^{t} \\
\end{array}$ & $\begin{array}{l}c_{4} \\
r_{i 4}^{t} \\
\end{array}$ & $\begin{array}{l}c_{5} \\
r_{i 5}^{t} \\
\end{array}$ & $\begin{array}{l}c_{6} \\
r_{i 6}^{t} \\
\end{array}$ \\
\hline \multicolumn{7}{|c|}{ Expert 1} \\
\hline$o_{1}$ & $s_{3}^{\prime}$ & $\left(s_{2}^{\prime},-0.5000\right)$ & $\left(s_{3}^{\prime}, 0.3143\right)$ & $\left(s_{4}^{\prime}, 0.1771\right)$ & $\left(s_{5}^{\prime}, 0.0729\right)$ & $s_{6}^{\prime}$ \\
\hline $\mathrm{O}_{2}$ & $s_{6}^{\prime}$ & $\left(s_{4}^{\prime}, 0.5000\right)$ & $\left(s_{4}^{\prime},-0.3409\right)$ & $\left(s_{6}^{\prime}, 0.0000\right)$ & $\left(s_{3}^{\prime}, 0.4732\right)$ & $s_{3}^{\prime}$ \\
\hline$o_{3}$ & $\left(s_{2}^{\prime},-0.5000\right)$ & $s_{3}^{\prime}$ & $\left(s_{6}^{\prime},-0.2475\right)$ & $\left(s_{5}^{\prime},-0.3105\right)$ & $\left(s_{4}^{\prime}, 0.0429\right)$ & $s_{3}^{\prime}$ \\
\hline$o_{4}$ & $s_{6}^{\prime}$ & $s_{6}^{\prime}$ & $\left(s_{3}^{\prime}, 0.3777\right)$ & $\left(s_{5}^{\prime},-0.2591\right)$ & $\left(s_{5}^{\prime},-0.2023\right)$ & $s_{6}^{\prime}$ \\
\hline$o_{5}$ & $\left(s_{4}^{\prime}, 0.5000\right)$ & $\left(s_{2}^{\prime},-0.5000\right)$ & $\left(s_{3}^{\prime}, 0.4954\right)$ & $\left(s_{4}^{\prime}, 0.0583\right)$ & $\left(s_{5}^{\prime}, 0.2671\right)$ & $s_{3}^{\prime}$ \\
\hline \multicolumn{7}{|c|}{ Expert 2} \\
\hline$o_{1}$ & $s_{2}^{\prime}$ & $s_{2}^{\prime}$ & $\left(s_{3}^{\prime}, 0.4294\right)$ & $\left(s_{4}^{\prime}, 0.1771\right)$ & $\left(s_{5}^{\prime},-0.0072\right)$ & $s_{3}^{\prime}$ \\
\hline $\mathrm{O}_{2}$ & $s_{5}^{\prime}$ & $s_{4}^{\prime}$ & $\left(s_{4}^{\prime},-0.2844\right)$ & $\left(s_{6}^{\prime}, 0.0000\right)$ & $\left(s_{3}^{\prime}, 0.1823\right)$ & $s_{5}^{\prime}$ \\
\hline$o_{3}$ & $s_{2}^{\prime}$ & $s_{3}^{\prime}$ & $\left(s_{6}^{\prime},-0.3709\right)$ & $\left(s_{5}^{\prime},-0.3105\right)$ & $\left(s_{4}^{\prime},-0.1591\right)$ & $s_{4}^{\prime}$ \\
\hline$o_{4}$ & $s_{4}^{\prime}$ & $s_{2}^{\prime}$ & $\left(s_{4}^{\prime}, 0.4890\right)$ & $\left(s_{5}^{\prime},-0.2591\right)$ & $\left(s_{5}^{\prime},-0.1744\right)$ & $s_{2}^{\prime}$ \\
\hline$o_{5}$ & $s_{6}^{\prime}$ & $s_{6}^{\prime}$ & $\left(s_{4}^{\prime},-0.3990\right)$ & $\left(s_{4}^{\prime}, 0.0583\right)$ & $\left(s_{5}^{\prime}, 0.3415\right)$ & $s_{6}^{7}$ \\
\hline \multicolumn{7}{|c|}{ Expert 3} \\
\hline$o_{1}$ & $s_{6}^{\prime}$ & $s_{2}^{\prime}$ & $\left(s_{4}^{\prime},-0.0771\right)$ & $\left(s_{4}^{\prime}, 0.1771\right)$ & $\left(s_{5}^{\prime},-0.1399\right)$ & $s_{3}^{\prime}$ \\
\hline$o_{2}$ & $s_{6}^{\prime}$ & $s_{6}^{\prime}$ & $\left(s_{4}^{\prime},-0.4021\right)$ & $\left(s_{6}^{\prime}, 0.0000\right)$ & $\left(s_{4}^{\prime},-0.3590\right)$ & $\left(s_{2}^{\prime},-0.5000\right)$ \\
\hline$o_{3}$ & $s_{3}^{\prime}$ & $s_{3}^{\prime}$ & $\left(s_{6}^{\prime},-0.2033\right)$ & $\left(s_{5}^{\prime},-0.3105\right)$ & $\left(s_{4}^{\prime},-0.4221\right)$ & $\left(s_{4}^{\prime}, 0.5000\right)$ \\
\hline$o_{4}$ & $\left(s_{2}^{\prime},-0.5000\right)$ & $s_{2}^{\prime}$ & $\left(s_{5}^{\prime}, 0.3542\right)$ & $\left(s_{5}^{\prime},-0.2591\right)$ & $\left(s_{5}^{\prime}, 0.1186\right)$ & $s_{6}^{\prime}$ \\
\hline$o_{5}$ & $\left(s_{4}^{\prime}, 0.5000\right)$ & $s_{4}^{\prime}$ & $\left(s_{4}^{\prime}, 0.2085\right)$ & $\left(s_{4}^{\prime}, 0.0583\right)$ & $\left(s_{5}^{\prime}, 0.0600\right)$ & $\left(s_{4}^{\prime}, 0.5000\right)$ \\
\hline \multicolumn{7}{|c|}{ Expert 4} \\
\hline$o_{1}$ & $s_{5}^{\prime}$ & $s_{6}^{\prime}$ & $\left(s_{4}^{\prime}, 0.2311\right)$ & $\left(s_{4}^{\prime}, 0.1771\right)$ & $\left(s_{5}^{\prime},-0.4538\right)$ & $\left(s_{2}^{\prime},-0.5000\right)$ \\
\hline $\mathrm{o}_{2}$ & $s_{6}^{\prime}$ & $s_{3}^{\prime}$ & $\left(s_{4}^{\prime}, 0.3925\right)$ & $\left(s_{6}^{\prime}, 0.0000\right)$ & $\left(s_{3}^{\prime}, 0.1537\right)$ & $s_{6}^{\prime}$ \\
\hline$o_{3}$ & $s_{3}^{\prime}$ & $s_{3}^{\prime}$ & $\left(s_{6}^{\prime}, 0.3131\right)$ & $\left(s_{5}^{\prime},-0.3105\right)$ & $\left(s_{3}^{\prime}, 0.4685\right)$ & $s_{3}^{\prime}$ \\
\hline$o_{4}$ & $s_{2}^{\prime}$ & $s_{6}^{\prime}$ & $\left(s_{6}^{\prime},-0.4682\right)$ & $\left(s_{5}^{\prime},-0.2591\right)$ & $\left(s_{5}^{\prime}, 0.0219\right)$ & $\left(s_{2}^{\prime},-0.5000\right)$ \\
\hline$o_{5}$ & $s_{4}^{\prime}$ & $s_{3}^{\prime}$ & $\left(s_{4}^{\prime},-0.3020\right)$ & $\left(s_{4}^{\prime}, 0.0583\right)$ & $\left(s_{5}^{\prime}, 0.0579\right)$ & $\left(\begin{array}{ll}s_{4}^{\prime}, & 0.5000)\end{array}\right.$ \\
\hline
\end{tabular}

Collective normalized ratings

\begin{tabular}{ccccccc} 
& $r_{i 1}$ & $r_{i 2}$ & $r_{i 3}$ & $r_{i 4}$ & $r_{i 5}$ \\
\hline$o_{1}$ & $\left(s_{4}^{\prime},-0.1124\right)$ & $\left(s_{2}^{\prime}, 0.1048\right)$ & $\left(s_{4}^{\prime},-0.3736\right)$ & $\left(s_{4}^{\prime}, 0.1771\right)$ & $\left(s_{5}^{\prime},-0.4084\right)$ & $\left(s_{3}^{\prime},-0.3356\right)$ \\
$o_{2}$ & $\left(s_{6}^{\prime},-0.1942\right)$ & $\left(s_{4}^{\prime},-0.1945\right)$ & $\left(s_{4}^{\prime},-0.0574\right)$ & $\left(s_{6}^{\prime}, 0.0000\right)$ & $\left(s_{3}^{\prime}, 0.2254\right)$ & $\left(s_{3}^{\prime}, 0.2416\right)$ \\
$o_{3}$ & $\left(s_{2}^{\prime}, 0.4012\right)$ & $\left(s_{3}^{\prime}, 0.0000\right)$ & $\left(s_{6}^{\prime},-0.3105\right)$ & $\left(s_{5}^{\prime},-0.3105\right)$ & $\left(s_{4}^{\prime},-0.3918\right)$ & $\left(s_{3}^{\prime}, 0.4325\right)$ \\
$o_{4}$ & $\left(s_{3}^{\prime},-0.4403\right)$ & $\left(s_{3}^{\prime}, 0.3624\right)$ & $\left(s_{5}^{\prime},-0.1034\right)$ & $\left(s_{5}^{\prime},-0.2591\right)$ & $\left(s_{5}^{\prime},-0.1505\right)$ & $\left(s_{3}^{\prime}, 0.1930\right)$ \\
$o_{5}$ & $\left(s_{5}^{\prime},-3456\right)$ & $\left(s_{3}^{\prime}, 0.3961\right)$ & $\left(s_{4}^{\prime},-0.1105\right)$ & $\left(s_{4}^{\prime}, 0.0583\right)$ & $\left(s_{5}^{\prime}, 0.1908\right)$ & $\left(s_{5}^{\prime},-0.3026\right)$ \\
\hline
\end{tabular}

TABLE 4: Interaction coefficient ranges between any two experts.

\begin{tabular}{lcccc}
\hline$I_{e}(i j)$ & $e_{1}$ & $e_{2}$ & $e_{3}$ & $e_{4}$ \\
\hline$e_{1}$ & {$[0.0000,0.0000]$} & {$[-0.0816,-0.0272]$} & {$[0.0296,0.0888]$} & {$[-0.0296,0.0296]$} \\
$e_{2}$ & {$[-0.0816,-0.0272]$} & {$[0.0000,0.0000]$} & {$[-0.0272,0.0272]$} & {$[0.0272,0.0816]$} \\
$e_{3}$ & {$[0.0296,0.0888]$} & {$[-0.0272,0.0272]$} & {$[0.0000,0.0000]$} & {$[0.0381,0.1143]$} \\
$e_{4}$ & {$[-0.0296,0.0296]$} & {$[0.0272,0.0816]$} & {$[0.0381,0.1143]$} & {$[0.0000,0.0000]$} \\
\hline
\end{tabular}

(3) The expressions of attribute ratings in this paper only cover linguistic terms, real values, interval values, and triangular fuzzy numbers. There exist the other expressions such as interval-valued fuzzy numbers [27] and uncertain linguistic terms [28]. In addition, this paper only involves benefit and cost criteria, but sometimes the other attribute types, such as targetbased criteria, also need to be considered. As to the target-based criteria, how to normalize the fuzzy hybrid ratings is another important future research direction.

(4) The proposed decision model for multiple attribute material selection considering attribute interactions under hybrid environment is a general method and can be easily extended to deal with other management 
decision making problems such as strategic management, human resource management, supply chain management, and investment management.

\section{Nomenclature}

\begin{tabular}{|c|c|}
\hline$\left(s_{k}^{G}, a_{k}\right):$ & $\begin{array}{l}\text { The } 2 \text {-tuple linguistic representation in } \\
\text { a linguistic term set with cardinality } \\
\text { being } G\end{array}$ \\
\hline$\left(s_{k^{\prime}}^{\prime}, a_{k^{\prime}}\right):$ & $\begin{array}{l}\text { The 2-tuple linguistic representation in } \\
\text { the basic linguistic term set }\end{array}$ \\
\hline$o_{i}:$ & Alternative $i$ \\
\hline$c_{j}:$ & Criterion $j$ \\
\hline$e_{t}:$ & Expert $t$ \\
\hline$f_{i j}^{t}:$ & $\begin{array}{l}\text { The raw rating of alternative } o_{i} \text { in } \\
\text { respect of } c_{j} \text { provided by } e_{t}\end{array}$ \\
\hline$r_{i j}^{t}:$ & $\begin{array}{l}\text { The normalized rating of alternative } o_{i} \\
\text { in respect of } c_{j} \text { provided by } e_{t}\end{array}$ \\
\hline$r_{i j}:$ & $\begin{array}{l}\text { The collective normalized rating of } \\
\text { alternative } o_{i} \text { in respect of } c_{j}\end{array}$ \\
\hline $\begin{array}{l}z_{i}: \\
u_{\widetilde{b}_{i j}}(\cdot):\end{array}$ & $\begin{array}{l}\text { The overall rating of alternative } o_{i} \\
\text { Membership function }\end{array}$ \\
\hline$\mu_{e}(\cdot):$ & Fuzzy measure for an expert \\
\hline$\mu_{c}(\cdot):$ & Fuzzy measure for an attribute \\
\hline$I_{e}(\cdot):$ & Shapley value for an expert \\
\hline$I_{c}(\cdot):$ & Shapley value for an attribute \\
\hline$m_{v_{e}}(\cdot):$ & Möbius representation for an expert \\
\hline$I_{e}(i j):$ & $\begin{array}{l}\text { Interaction index between any two } \\
\text { experts }\end{array}$ \\
\hline$I_{c}(i j):$ & $\begin{array}{l}\text { Interaction index between any two } \\
\text { attributes }\end{array}$ \\
\hline MADM: & Multiattribute decision making \\
\hline BLTS: & The basic linguistic term set \\
\hline LWGAI: & $\begin{array}{l}\text { Linguistic weighted geometric } \\
\text { averaging with interaction }\end{array}$ \\
\hline LHWGAI: & $\begin{array}{l}\text { Linguistic hybrid weighted geometric } \\
\text { averaging with interaction }\end{array}$ \\
\hline ANP: & Analytic network process \\
\hline AHP: & Analytic hierarchy process. \\
\hline
\end{tabular}

\section{Conflict of Interests}

On behalf of the coauthors, the authors declare that there is no conflict of interests regarding the publication of this paper.

\section{References}

[1] H. M. Tawancy, A. Ul-Hamid, A. I. Mohammed, and N. M. Abbas, "Effect of materials selection and design on the performance of an engineering product-an example from petrochemical industry," Materials \& Design, vol. 28, no. 2, pp. 686-703, 2007.

[2] S. Khare, M. Dell'Amico, C. Knight, and S. McGarry, "Selection of materials for high temperature sensible energy storage," Solar Energy Materials \& Solar Cells, vol. 115, pp. 114-122, 2013.

[3] K.-P. Lin, H.-P. Ho, K.-C. Hung, and P.-F. Pai, "Combining fuzzy weight average with fuzzy inference system for material substitution selection in electric industry," Computers \& Industrial Engineering, vol. 62, no. 4, pp. 1034-1045, 2012.
[4] L. Anojkumar, M. Ilangkumaran, and V. Sasirekha, "Comparative analysis of MCDM methods for pipe material selection in sugar industry," Expert Systems with Applications, vol. 41, no. 6, pp. 2964-2980, 2014.

[5] C. Wu and D. Barnes, "Formulating partner selection criteria for agile supply chains: a Dempster-Shafer belief acceptability optimisation approach," International Journal of Production Economics, vol. 125, no. 2, pp. 284-293, 2010.

[6] A. Jahan, M. Y. Ismail, S. M. Sapuan, and F. Mustapha, "Material screening and choosing methods-a review," Materials \& Design, vol. 31, no. 2, pp. 696-705, 2010.

[7] A.-H. Peng and X.-M. Xiao, "Material selection using PROMETHEE combined with analytic network process under hybrid environment," Materials \& Design, vol. 47, pp. 643-652, 2013.

[8] M. F. Ashby, Y. J. M. Bréchet, D. Cebon, and L. Salvo, "Selection strategies for materials and processes," Materials \& Design, vol. 25, no. 1, pp. 51-67, 2004.

[9] D.-F. Li and S.-P. Wan, "Fuzzy heterogeneous multiattribute decision making method for outsourcing provider selection," Expert Systems with Applications, vol. 41, no. 6, pp. 3047-3059, 2014.

[10] A. Jahan, F. Mustapha, S. M. Sapuan, M. Y. Ismail, and M. Bahraminasab, "A framework for weighting of criteria in ranking stage of material selection process," International Journal of Advanced Manufacturing Technology, vol. 58, no. 1-4, pp. 411420, 2012.

[11] P. Karande, S. K. Gauri, and S. Chakraborty, "Applications of utility concept and desirability function for materials selection," Materials \& Design, vol. 45, pp. 349-358, 2013.

[12] H.-C. Liu, L.-X. Mao, Z.-Y. Zhang, and P. Li, "Induced aggregation operators in the VIKOR method and its application in material selection," Applied Mathematical Modelling, vol. 37, no. 9, pp. 6325-6338, 2013.

[13] G. U. Wei, X. F. Zhao, R. Lin, and H. J. Wang, “Generalized triangular fuzzy correlated averaging operator and their application to multiple attribute decision making," Applied Mathematical Modelling, vol. 36, no. 7, pp. 2975-2982, 2012.

[14] M.-L. Tseng, J. H. Chiang, and L. W. Lan, "Selection of optimal supplier in supply chain management strategy with analytic network process and choquet integral," Computers and Industrial Engineering, vol. 57, no. 1, pp. 330-340, 2009.

[15] Z. B. Wu and Y. H. Chen, "The maximizing deviation method for group multiple attribute decision making under linguistic environment," Fuzzy Sets and Systems, vol. 158, no. 14, pp. 16081617, 2007.

[16] F. Herrera and L. Martinez, "A 2-tuple fuzzy linguistic representation model for computing with words," IEE Transactions on Fuzzy Systems, vol. 8, no. 66, pp. 746-752, 2000.

[17] F. Herrera, L. Martínez, and P. J. Sánchez, "Managing nonhomogeneous information in group decision making," European Journal of Operational Research, vol. 166, no. 1, pp. 115-132, 2005.

[18] C. Q. Tan, "A multi-criteria interval-valued intuitionistic fuzzy group decision making with Choquet integral-based TOPSIS," Expert Systems with Applications, vol. 38, no. 4, pp. 3023-3033, 2011.

[19] M. Grabisch, " $k$-order additive discrete fuzzy measures and their representation," Fuzzy Sets and Systems, vol. 92, no. 2, pp. 167-189, 1997. 
[20] J.-L. Marichal, “Entropy of discrete Choquet capacities," European Journal of Operational Research, vol. 137, no. 3, pp. 612-624, 2002.

[21] R. V. Rao and J. P. Davim, "A decision-making framework model for material selection using a combined multiple attribute decision-making method," The International Journal of Advanced Manufacturing Technology, vol. 35, no. 7-8, pp. 751760, 2008.

[22] J.-Z. Wu, Q. Zhang, and S.-J. Sang, "Supplier evaluation model based on fuzzy measures and choquet integral," Journal of Beijing Institute of Technology, vol. 19, no. 1, pp. 109-114, 2010.

[23] Z. S. Xu, "A method based on linguistic aggregation operators for group decision making with linguistic preference relations," Information Sciences, vol. 166, no. 1-4, pp. 19-30, 2004.

[24] G.-W. Wei, "A method for multiple attribute group decision making based on the ET-WG and ET-OWG operators with 2tuple linguistic information," Expert Systems with Applications, vol. 37, no. 12, pp. 7895-7900, 2010.

[25] Z. S. Xu, "An overview of methods for determining OWA weights," International Journal of Intelligent Systems, vol. 20, no. 8, pp. 843-865, 2005.

[26] G. Büyüközkan, O. Feyzioğlu, and M. S. Ersoy, "Evaluation of 4PL operating models: a decision making approach based on 2additive Choquet integral," International Journal of Production Economics, vol. 121, no. 1, pp. 112-120, 2009.

[27] S.-J. Chen and S.-M. Chen, "Fuzzy risk analysis based on measures of similarity between interval-valued fuzzy numbers," Computers \& Mathematics with Applications, vol. 55, no. 8, pp. 1670-1685, 2008.

[28] Z. S. Xu, "Induced uncertain linguistic OWA operators applied to group decision making," Information Fusion, vol. 7, no. 2, pp. 231-238, 2006. 

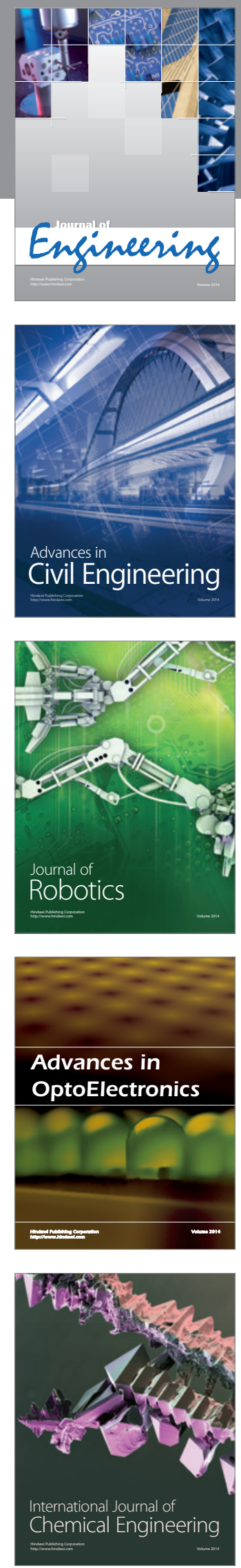

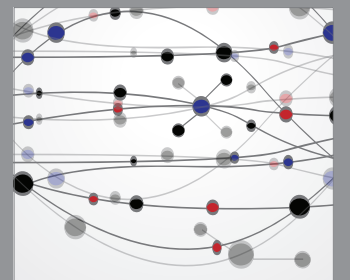

The Scientific World Journal
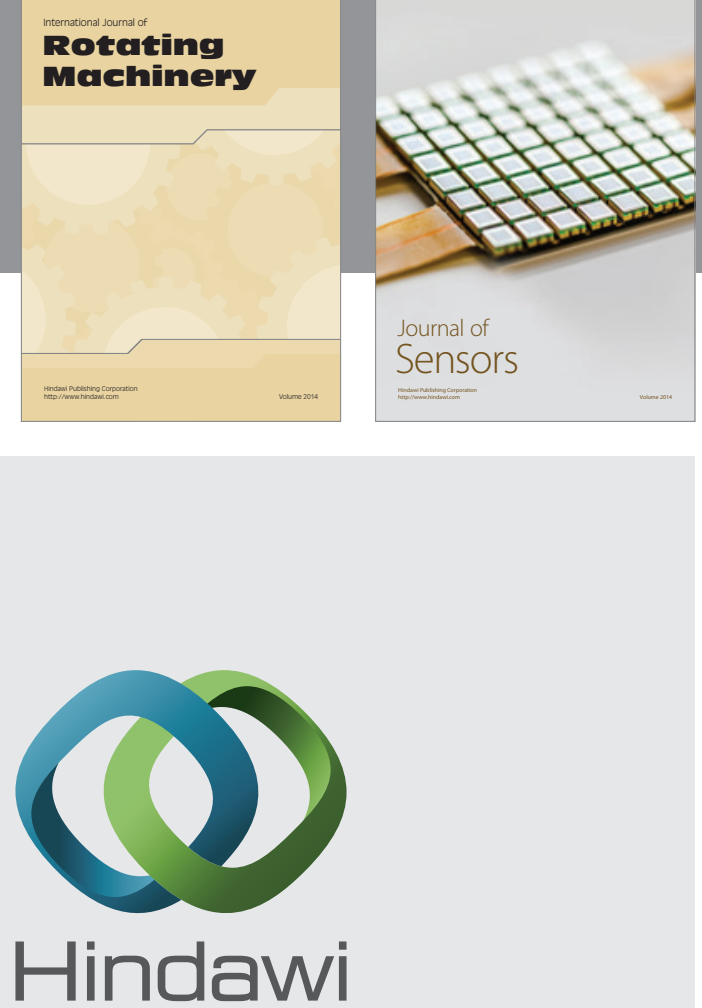

Submit your manuscripts at http://www.hindawi.com
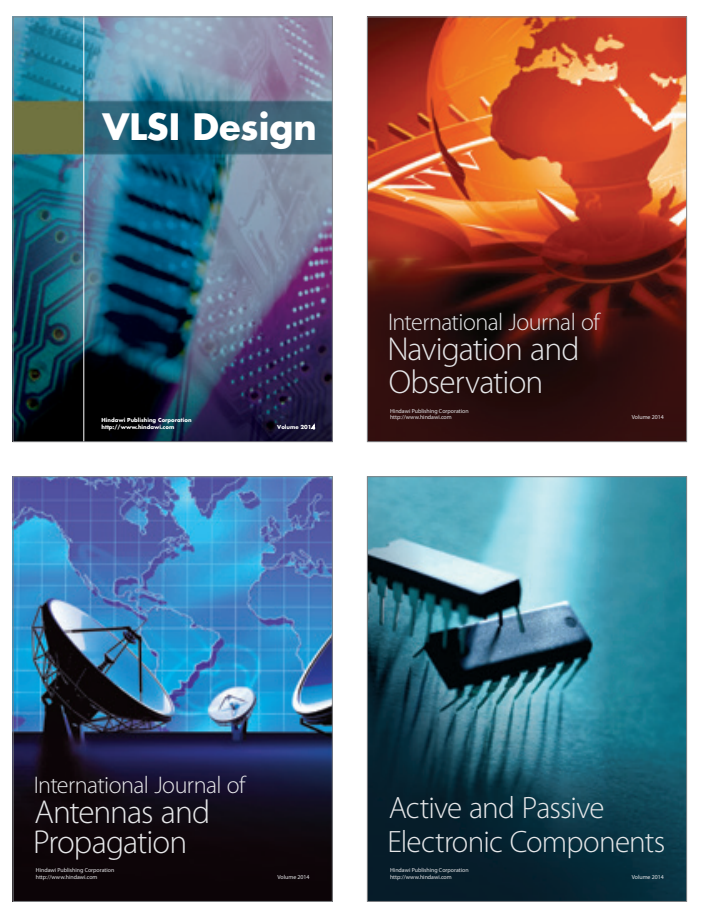
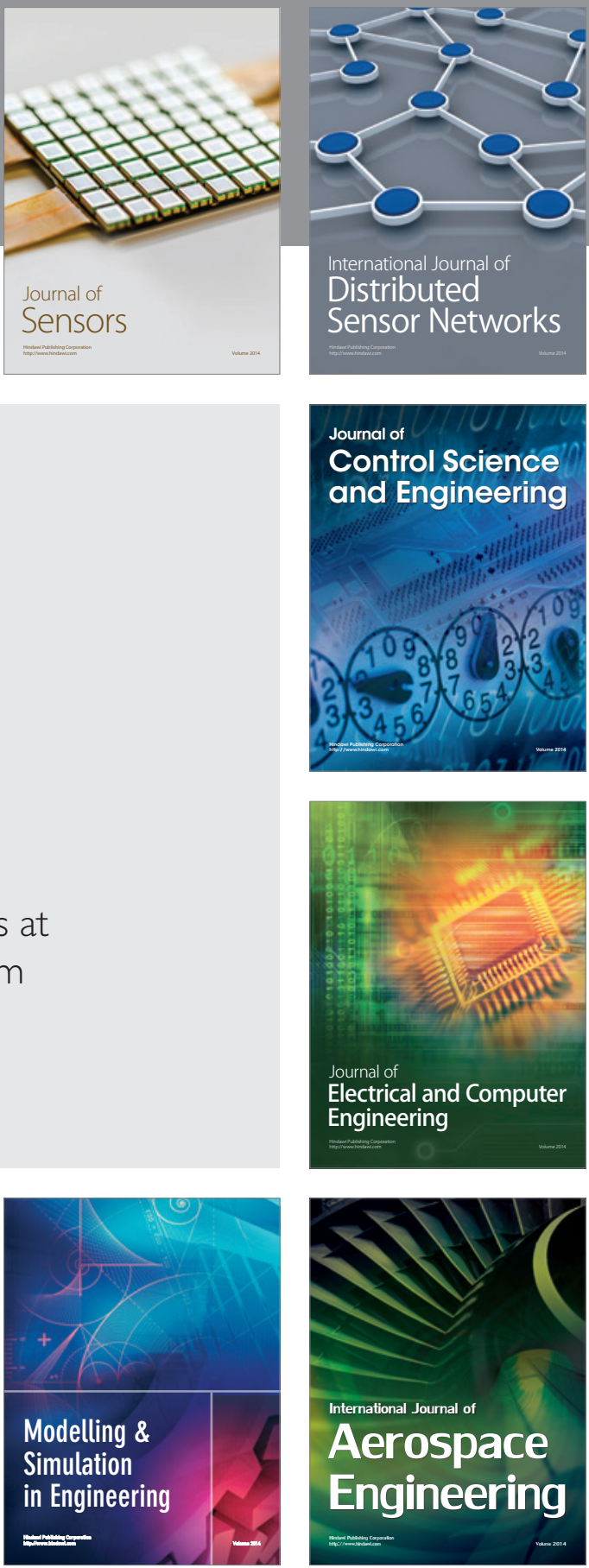

Journal of

Control Science

and Engineering
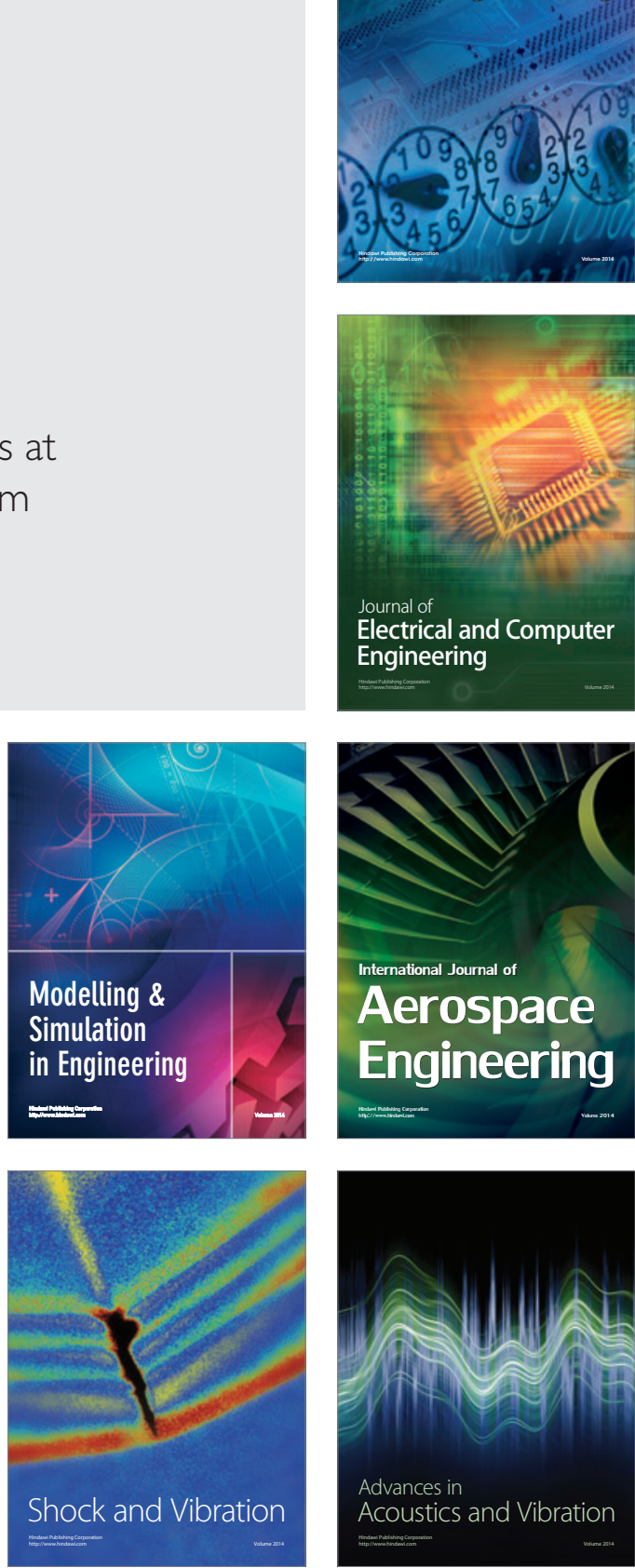